\title{
An Insight To Pullulan: A Biopolymer in Pharmaceutical Approaches
}

\author{
Deepak Kumar, Nisha Saini, Vinay Pandit, Sajid Ali* \\ School of Pharmaceutical Sciences, Shoolini University, Solan (H.P), India \\ Email: deepakkaushik354@gmail.com \\ School of Pharmaceutical Sciences, Shoolini University, Solan (H.P), India \\ Email: nishasaini10287@gmail.com \\ School of Pharmaceutical Sciences, Shoolini University, Solan (H.P), India \\ Email: vinay2121@gmail.com \\ School of Pharmaceutical Sciences, Shoolini University, Solan (H.P), India \\ Email: sajidalipharma4u@gmail.com
}

\begin{abstract}
Pullulan is a non-ionic polysaccharide obtained from fermentation of black yeast like Aureobasidium pullulans and is currently exploited in food and pharmaceutical industries due to its unique characteristics. Due to its properties like non-toxic, non-immunogenic, noncarcinogenic, non-mutagenic, pullulan is being explored for various biomedical applications viz., gene delivery, targeted drug therapy, tissue engineering, wound healing, and also being used in diagnostic applications like, perfusion, receptor, and lymph node target specific imaging and vascular compartment imaging. The unique linkage of $\alpha$ $(1 \rightarrow 4)$ and $\alpha(1 \rightarrow 6)$ in pullulan endows this polymer with distinctive physical traits, including adhesive property and the ability to form fibres. This review article presents an overview of properties, production, derivatives of pullulan, and recent advances of pullulan.
\end{abstract}

Keywords: Pullulan; Polysaccharide; Biomedical; Diagnostic application; Medical imaging; Linkage.

\section{Introduction}

Biopolymers are the generally water soluble gums, produced by a variety of micro-organism, which have novel and unique physical properties. Because of these properties, these have found a wide range of applications in food, pharmaceutical and other companies. Some of the applications include their use as 
emulsifiers, stabilizers, binders, gelling agents, coagulants, lubricants, film formers, thickening agents and suspending agents. Advances in technology occur due to the exploitation of properties offered by new polymeric materials like blends, composites, etc. Blend of polymers are prepared by physical mixing of two or more polymers. The resulting blending system has the property superior to any one of the individual polymer [1-3]. Pullulan is one of the polymers obtained from the fermentation medium of the black yeast like Aureobasidium pullulans (as it forms a black pigment, melanin so called black yeast) [4]. It shows activity against for enzymes such as invertase, amylases, glucose oxidase, $\beta$-glusosidase, frutosyltransferase, and small quantities of proteolytic enzyme [5-7]. Pullulan was first reported by Bernier in 1958 and the structure was elaborated by Bender et al in 1959 [8]. It comprises of maltotrose units connected by $\alpha(1 \rightarrow 4)$ glycosidic bond, whereas consecutive maltotriose units are connected to each other by $\alpha$ $(1 \rightarrow 6)$ glycosidic linkages. Basic linkages in pullulan and its enzymatic hydrolysis sites are shown in fig. 1 .

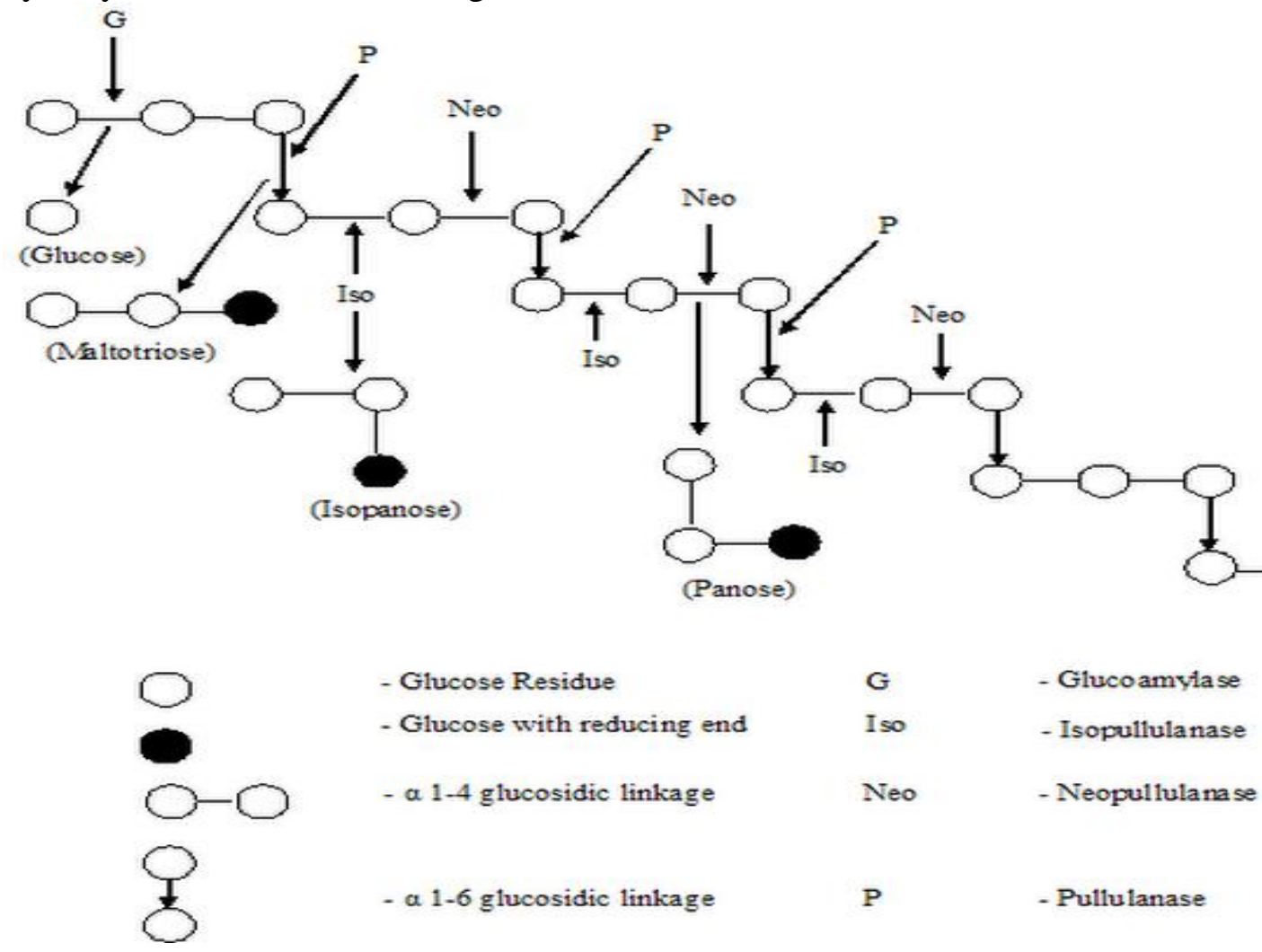

Fig. 1: Basic linkages in pullulan and enzymatic hydrolysis site

Structure of pullulan and pullulan acetate are shown in fig. 2 and fig. 3 respectively. The application of pullulan is emerging as a source of polymeric materials, which are economical and competitive with the natural gums produced from marine algae and other plants [9]. Applications of pullulan biopolymer are 
based on biodegradability of the polymer, so it is packed in food packaging films, coating of food containers for perishable fruit and vegetables [10].

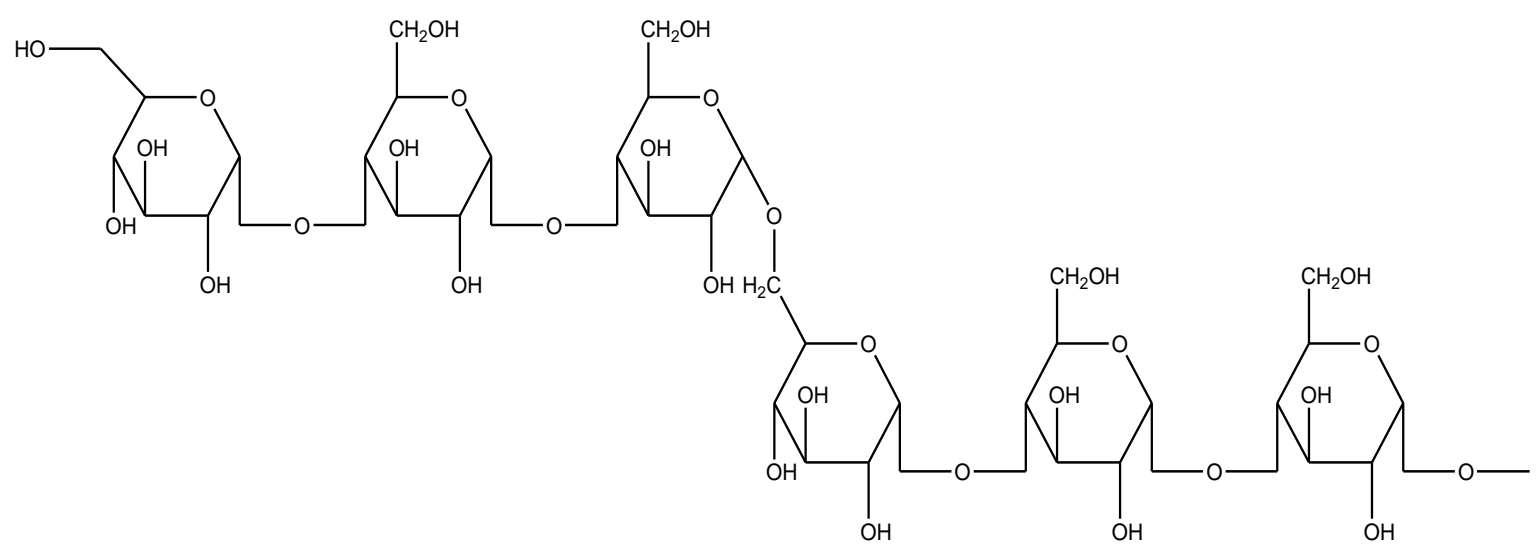

Fig. 2: Structure of pullulan

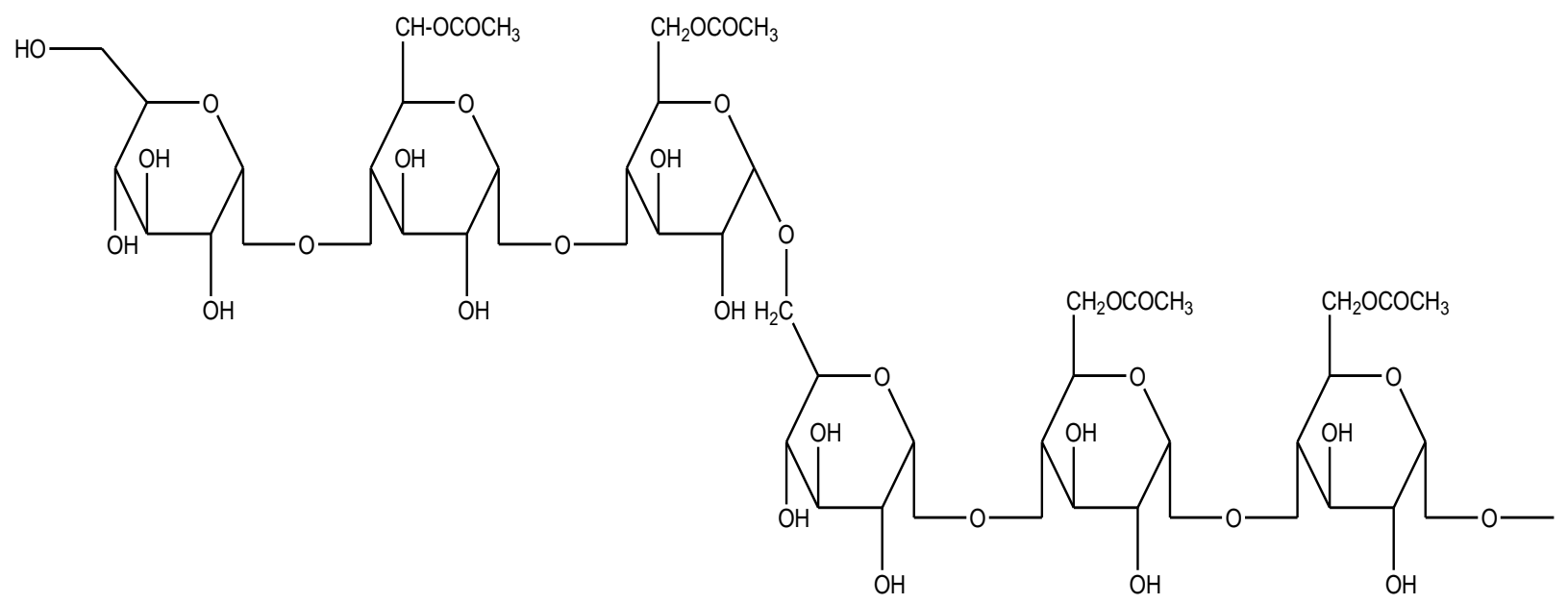

Fig. 3: Structure of pullulan acetate

\section{Historical Aspects Related to Pullulan}

Origin of pullulan occurred 6-7 decades earlier i.e. in 1950s. Aureobasidium pullulans was first described as Dematium pullulans by De Bary. Bernier was the first to isolate pullulan form Aureobasidium pullulans in 1958. Bender et al studied the novel polysaccharides in 1959 and named it pullulan. In 1960s, the basic structure of pullulan was resolved [11]. They discovered the enzyme pullulanase, which hydrolyses $\alpha-(1 \rightarrow 6)$ linkages in pullulan and converts to maltotriose. Thus, pullulan is viewed as $\alpha-(1 \rightarrow 6)$ linked polymer of maltotriose 
subunits. Cately and his coworkers established the occurrence of randomly distributed maltotetraose [12].

Pullulan has the safe history of use in Japan as a food ingredient and as pharmaceutical bulking agent. The main use of pullulan has been as a glazing agent having oxygen barrier properties [13]. It has Generally Regarded As Safe (GRAS) status in US for a wide range of applications. Human volunteer studies have only reported the abdominal fullness at doses of $10 \mathrm{~g}$ pullulan per day with some mild gastrointestinal symptoms at higher doses. Pullulan is accepted for use as an excipient in pharmaceutical tablets and is listed in the Japanese Standards for Ingredients for drugs [14,15].

The commercial production of pullulan began in 1976 by the Hayashibra Company, in Okayama Japan [16]. Pullulan production was an outgrowth of starch syrup production, noted in 1883. Pullulan films were commercialized by Hayashibara in 1982.

\section{Properties of Pullulan}

Dry pullulan is white to off-white tasteless, odourless powder which forms a viscous non-hygroscopic solution when dissolved in water at 5-10\%. Pullulan starts to decompose at $250{ }^{\circ} \mathrm{C}$ and chars at $280{ }^{\circ} \mathrm{C}$. it is highly soluble in water, dilute alkali, insoluble in alcohol and other organic solvents expect dimethylsulphoxide and formamide. As pullulan is highly water soluble so it can be used as a carrier for drug and it helps in controlled release of drug in plasma. It has the molecular weight within the range of $5000-9000000 \mathrm{~g} / \mathrm{mol}$ with straight unbranched chain and is very flexible molecule having the property of "random coil" (depending on sedimentation coefficient and intrinsic viscosity measurement). Pullulan is non-toxic, non-mutagenic, non-carcinogenic, odorless, tasteless, and edible [17,18]. Furthermore, pullulan has a considerable mechanical strength and other functional properties viz. adhesiveness, film formability, enzymatically - mediated degradability [19].

Pullulan is biodegradable, impermeable to oxygen, and is not attacked by the digestive enzymes of the human gut, hence can be used as carrier for oral delivery of drug. Pullulans solutions have relatively low viscosity, resembling gum arabic [16]. It can be used as low-viscosity filler in berverages and sauces. The viscosity of pullulan solution doesn't change with heat, change in $\mathrm{pH}$, and most metal ions including sodium chloride.

\section{Production of Pullulan}

Pullulan is usually produced on industrial scale by the fermentation of liquefied starch under specified parameters using a specific, not genetically modified, nonpathogenic and non-toxigenic strain of Aureobasidium pullulans. 


\subsection{Pullulan production by fermentation}

The production of pullulan depends on the fermentation parameters viz., the morphological state and the fungal strains. In commercial production [16], Aureobasidium pullulans is cultivated on medium, comprises of starch hydrolysates of dextran equivalent to $40-50$, at $10-15 \%$ concentration. The fermentation medium consists of peptone, phosphate and basal salts. The $\mathrm{pH}$ of the culture media is initially adjusted to $\mathrm{pH} 6.5$, which falls during the first 24 hours to a $\mathrm{pH}$ of 3.5. Maximal growth of culture media occurs within 75 hours. Optimal pullulan yields are obtained within about 100 hours. Cultures are stirred, aerated, and the temperature is maintained at temperature of $30{ }^{0} \mathrm{C}$. Yield of greater than $70 \%$ of initial substrate is claimed. Culture conditions and strain selection are important parameters in obtaining high molecular weight pullulan, which is relatively free of melanin. Aureobasidium pullulans cells are removed from media by filtration of diluted culture broth. Melanin is removed by treating it with activated charcoal. Pullulan is recovered and purified by precipitation with organic solvents, particularly alcohol. It may be further purified by the use of ultrafiltration and ion exchange resins.

Youssef et al reported the production of pullulan by using various strains of $A$. pullulans using sucrose and glucose in shaking flask and stirred tank fermenters. They reported maximum concentration of pullulan at $31.3 \mathrm{~g} / \mathrm{L}$ with pullulan productivity of $4.5 \mathrm{~g} / \mathrm{L}$ per day [20]. In another study Shabtai and his co-workers produced pullulan in a two stage fermentation process with increased productivity. In the first step, fermentation was carried out using soyabean oil as a carbon source and glutamate as nitrogen source, at $\mathrm{pH}$ of 4.5 , which resulted in the concentration of pullulan at $15 \mathrm{~g} / \mathrm{L}$. In the second stage, the cells were shifted to production, which was carried out using sucrose as a carbon source with nitrogen limitation. They reported the concentration of pullulan about $35 \mathrm{~g} / \mathrm{L}$ in 50 hours [21]. Recently, Roukas with his co-workers observed maximum concentration of pullulan of $30 \mathrm{~g} / \mathrm{L}$ in an air-lift fermentor at an aeration rate of $2 \mathrm{vvm}$ ( $\mathrm{vol} / \mathrm{vol} / \mathrm{min}$ ). West T. P., et al, 1991 produced the pullulan in two cycle process of 165 hours, using either agar or calcium alginate for immobilized cell system. The cells which were immobilized in alginate gave a higher production of pullulan with $4.2 \mathrm{mg}$ pullulan per gram cells per hour during the first cycle and $4.6 \mathrm{mg}$ per gram cells per hour during the next cycle [22].

\subsubsection{By using coconut by-products}

Thirumavalavan et al synthesized pullulan from coconut by-products using Aureobasidium pullulans. The strain was maintained on agar slants at $4{ }^{\circ} \mathrm{C}$ and subcultured every fortnight time interval. The seed medium comprises of sucrose, potassium dihydrogen phosphate, yeast extract, ammonium sulphate, sodium chloride and distilled water. The medium was autoclaved for $15 \mathrm{~min}$ at $121{ }^{\circ} \mathrm{C}$, cooled and the $\mathrm{pH}$ was adjusted to 7 . Then the culture was incubated at $30{ }^{\circ} \mathrm{C}$ for 
36 hours in a rotary shaker incubator at $200 \mathrm{rpm}$. The highest concentration of pullulan was $54 \mathrm{~g} / \mathrm{L}$ in coconut milk [23].

\subsubsection{By beet molasses:}

Goksungur and his co-workers produced pullulan by beet molasses using $A$. pullulan. The media comprised of sucrose, ammonium sulphate, yeast, potassium dihydrogen phosphate, magnesium sulphate, and sodium chloride. They reported the highest pullulan concentration $35 \mathrm{~g} / \mathrm{L}$ obtained in molasses treated with sulphuric acid and activated carbon [24].

\subsubsection{From agro-industrial waste:}

Pullulan can be sysnthesized from a various carbohydrate substrates incorporated into defined (synthetic) or non-defined media. The latter covers the agro-industrial wastes, which have been shown to be suitable for pullulan production $[25,26]$. The utilization of these substrates for the production of pullulan seems to be economically advantageous and economically sound.

Different fermentation parameters for the production of pullulan have been studied with defined substrates viz. glucose and sucrose, but the results from the agro-industrial wastes have shown that higher or similar yield of pullulan can be obtained as compared to conventional substrate [27]. Also, pullulan produced by such fermentations is characterized by heterogenecityof both composition and molecular weight [28]. Following are the agro-industrial wastes which have been used for the production of pullulans:

- Grape skin pulp [28]

- Molasses [28]

- Starch waste [29]

- Olive oil wastes $[28,30]$

- Carob pod [22]

\subsection{Biosynthesis of pullulan}

Significant work has been done in recent years to determine the pathways for biosynthesis of polysaccharides like pullulan. Taguchi et al noted the biosynthesis of pullulan cell free preparations and acetone dried cells. Frozen cells were disrupted by grinding by alumina. The debris was removed by centrifugation. The precipitation of supernatant was done with $80 \%$ saturated ammonium sulphate solution. This protein precipitate catalyzed biosynthesis of pullulan from Uridine5-diphosphoglucose (UDPG) and ATP gave the yield of 54\% of pullulan with respect to the amount of UDPG added [31]. 


\section{Semi Synthetic Derivatives of Pullulan}

Pullulan can be easily derivatized in order to enhance its activity and widen the window of its applications. Pullulan can be derivatized in various ways, which are given below:

\subsection{Chemical modification}

Pullulan can be derivatized to enhance its applications by grafting different chemical structures on the backbone. Pullulan consists of nine hydroxyl groups for the substitution reactions on the repeating unit. The relativities of these hydroxyl groups also depend on the polarity of the solvent and the reagents. The hydroxyl groups of pullulan were subjected to various chemical reactions, leading to the formation of a large number of derivatives, which are given in table 1 [32].

Table 1: Schematic chemical structures of the most common pullulan derivatives:

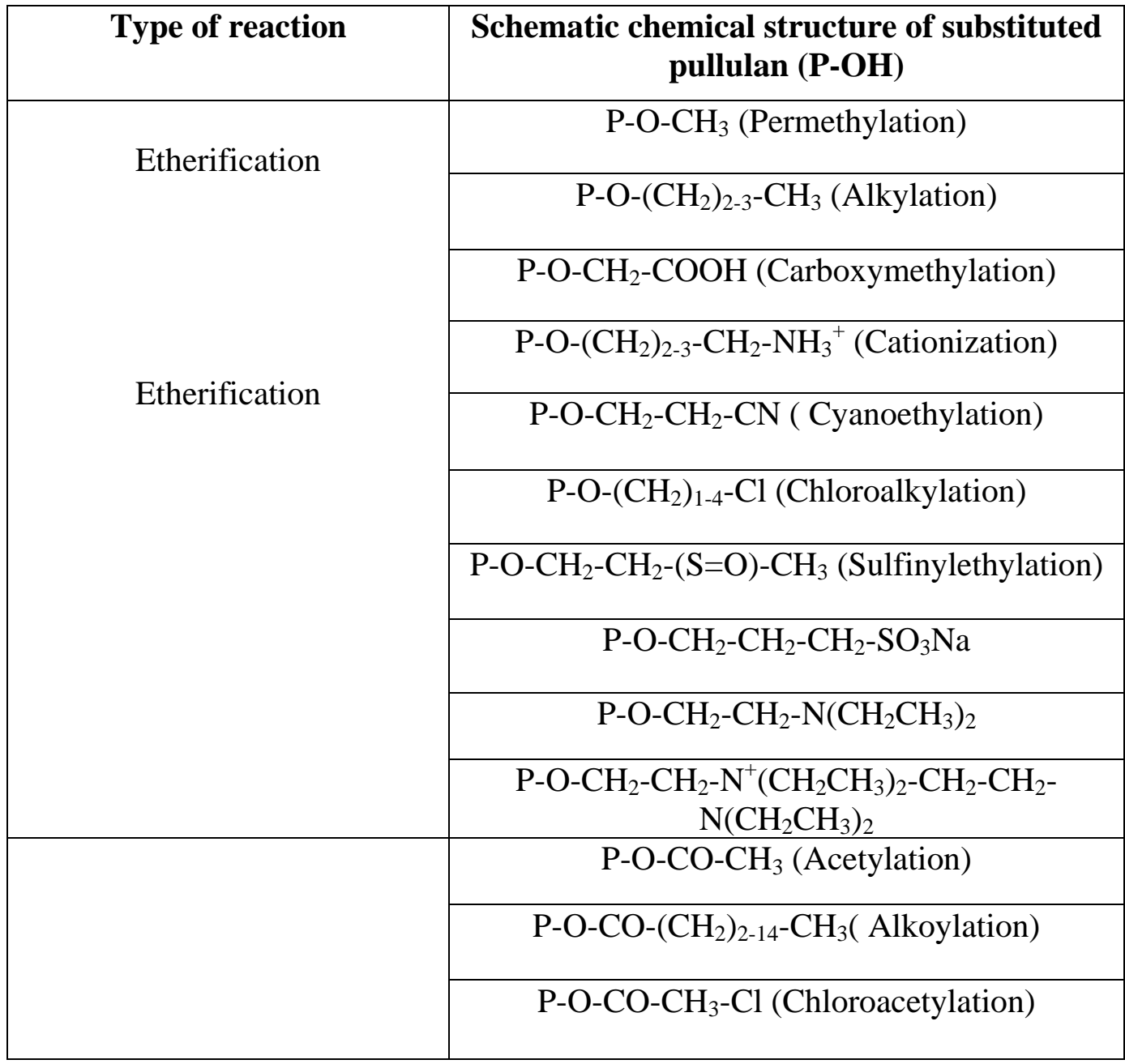




\begin{tabular}{|c|c|}
\hline \multirow{9}{*}{ Esterification } & $\mathrm{P}-\mathrm{O}-\mathrm{CO}-\mathrm{CH}_{2}-\mathrm{CH}_{2}-\mathrm{COOH}$ (Succinoylation) \\
\hline & PA-O-CO- $\mathrm{CH}_{2}-\mathrm{CH}_{2}-\mathrm{CO}$-Sulfodimethoxine ${ }^{\mathrm{a}}$ \\
\hline & $\mathrm{P}-\mathrm{O}-\mathrm{CO}-\mathrm{CH}_{2}-\mathrm{CH}_{2}-\mathrm{CO}-$ Cholesterol $^{\mathrm{b}}$ \\
\hline & P-abietate \\
\hline & P-strearate \\
\hline & PA-folate ${ }^{a}$ \\
\hline & P-cinnamate \\
\hline & P-biotin \\
\hline & $\mathrm{P}-\mathrm{O}-\mathrm{SO}_{2}-\mathrm{CH}_{3}$ \\
\hline \multirow[t]{3}{*}{ Urethane Derivatives } & $\begin{array}{c}\text { P-O-CO-NH-CH }-\mathrm{CH}(\mathrm{OH})-\mathrm{CH}_{3} \\
\text { P-O-CO-NH- } \mathrm{CH}_{2}-\mathrm{CH}_{2}-\mathrm{NH}_{3}{ }^{+}\end{array}$ \\
\hline & P-O-CO-NH-R (R=Phenyl or hexyl) \\
\hline & P-O-CO-NH-phenyl \\
\hline $\begin{array}{c}\text { Urethane } \\
\text { derivativel amidification }\end{array}$ & P-O-CO-NH- $\left(\mathrm{CH}_{2}\right)_{6}-\mathrm{NH}-\mathrm{CO}$-chloresterol \\
\hline Chlorination & $\mathrm{P}-\mathrm{CH}_{2}-\mathrm{Cl}\left(\mathrm{C}_{6}\right.$ Substitution $)$ \\
\hline Sulfation & $\mathrm{P}-\mathrm{O}-\mathrm{SO}_{3} \mathrm{Na}$ \\
\hline Azido-pullulan & $\mathrm{P}-\mathrm{CH}_{2}-\mathrm{N}_{2}$ \\
\hline \multirow[t]{2}{*}{ Oxidation } & $\mathrm{P}-\mathrm{COOH}\left(\mathrm{C}_{6}\right.$ Oxidation $)$ \\
\hline & Glycosidic ring opening ( periodate oxidation) \\
\hline \multirow{2}{*}{$\begin{array}{l}\text { CMP/ hydrazone } \\
\text { derivatives }\end{array}$} & $\mathrm{P}-\mathrm{O}-\mathrm{CH}_{2}-\mathrm{CO}-\mathrm{NH}$-doxorubicin \\
\hline & $\mathrm{P}-\mathrm{O}-\mathrm{CH}_{2}-\mathrm{CO}-\mathrm{NH}$-antibody \\
\hline \multirow[t]{2}{*}{ CMP/ amidification ${ }^{\mathrm{c}}$} & $\mathrm{P}-\mathrm{O}-\mathrm{CH}_{2}-\mathrm{CO}-\mathrm{NH}-\mathrm{CH}_{2}-\left(\mathrm{CH}_{2}\right)_{14}-\mathrm{CH} 3$ \\
\hline & $\begin{array}{c}\mathrm{P}-\mathrm{O}-\mathrm{CH}_{2}-\mathrm{O}-\mathrm{CO}-\mathrm{C}\left(\mathrm{CH}_{3}\right)_{2}-\mathrm{R} \\
\text { with } \mathrm{R}=\text { poly(methacrylate), } \\
\text { poly(methylmethacrylate) }\end{array}$ \\
\hline
\end{tabular}




\section{Applications of Pullulan}

\subsection{Biomedical and Pharmaceutical applications:}

The use of pullulan in biomedical field is emerging contemporarily due to its properties viz., non-toxic, non-immunogenic, biocompatible, and inert nature.

\subsubsection{Tissue engineering and grafting}

The surface and the bulk property of any biomaterial is important as it influences the dynamic reactions that take place at tissue implant interface. These properties or the change in the property which can take place over time in-vivo, should be known for designing the biomaterial for specific applications and this can be easily done with pullulan. $\mathrm{Na}$ and his co-workers conjugated the pullulan with an interferon-water-soluble low molecular weight recombinant protein which had both anti-viral and immunoregulatory activity. This allowed the user to preserve the biological activity of the drug while enhancing its liver accumulation [39]. Surface modification is an utmost tool for tissue engineering purpose. The surface modification can be easily done with pullulan as it comprises nine hydroxyl groups for substation reactions on the repeating unit.

Applications of pullulan can be enhanced by grafting different chemical groups on it as it contains nine hydroxyl groups, which can be easily substituted. The weight of pullulan increases when grafting is done. The increase in weight of pullulan after grafting clearly indicates the grafting of concerned group on to pullulan. Gao et al characterized the graft yield, which is shown below [40]:

$$
\begin{aligned}
\text { Grafting ratio } \% \mathrm{G} & =\frac{\text { Weight of the grafted chain }}{\text { Weight of pullulan }} \times 100 \\
\text { Grafting Efficiency } \% \mathrm{E} & =\frac{\text { Weight of the grafted chain }}{\text { Weight of polymer formed }} \times 100 \\
\text { Grafting ratio } \% \mathrm{G} & =\frac{\text { Weight of the polymer used }}{\text { Weight of the monomer used }} \times 100
\end{aligned}
$$

\subsubsection{Pullulan as a carrier for drug delivery}

Stimuli-sensitive polymer systems have been used as materials for the delivery of drug $[41,42]$. Gheorge et al grafted poly(N-isopropylacrylamide-co-acrylamide) onto the pullulan in order to confer their temperature sensitivity. Then the remaining hydroxyl groups of the pullulan were reacted with succinic anhydride 
to introduce the $\mathrm{pH}$-sensitive units $(-\mathrm{COOH})$, resulting into the more hydrophilic nature than the native pullulan [43]. Thus, $\mathrm{pH}$-sensitive pullulan microspheres can be prepared for controlled delivery of the drug.

- Liver targeting study focuses on the blood compatibility of the cationic pullulan, physico-chemical characterization, uptake of nanocomplex by hapatocytes and in-vitro transfection. Liver targeting can be achieved by using drug loaded pullulan. $\mathrm{Xi}$ and his co-workers studied the liver binding affinity of the modified pullulan in-vitro in hepatocytes and in-vivo in mice [44].

- Pullulan can be used for tumour cell targeting. Scomparin et al designed two new anti-cancer polymers for tumour cell targeting. Pullulan was derivatized with either doxorubicin or doxorubicin and folic acid. Then, pullulan was activated by periodate oxidation and functionalized by reductive conjugation cysteamine and $1.9 \mathrm{kDa}$ ammonium polyethyleneglycol [PEG $\left.\left(\mathrm{NH}_{2}\right)\right]$ [45]. This study suggests that doxorubicin-pullulan bioconjugates possess suitable properties for passive tumour targeting while folic acid conjugate of pullulan has a limited effect on selective cell uptake.

\subsubsection{Pullulan as a carrier for gene delivery:}

Application of pullulan to the gene delivery is being explored. Gene therapy using viruses have been performed, but the major drawback of using viruses is that they are immunogenic, disease causing and can be hazardous to health. Pullulan being non-toxic and biocompatible is investigated for gene delivery application. Hosseinkhani et al mixed the pullulan derivative with a plasmid DNA in aqueous solution containing zinc ions to obtain the conjugate of pullulan derivative with plasmid DNA with $\mathrm{Zn}^{2+}$ coordination [46].

\subsubsection{Medical imaging:}

Recently nanotechnology has been used for earlier detection of cancerous cell in the body. Quantum dots, which are the nano-size semiconductor particles has attracted many scientists in biological field. They are used as fluorescent probes for cell tracking. Hasegawa et al developed cholesterol pullulan and amino group modified cholesterol pullulan nanaogels for the delivery of quantum dots into cells in comparison to conventional cationic liposome which has the disadvantage of forming aggregates ones gets into the cells. Nanoparticles were prepared by mixing nanogels of derivatized pullulan with quantum dots. They reported the intensity of fluorescence per cell and compared with liposomal-quantum dots complex. The particles with higher number of amino group showed fluorescence 
up to 3-4 times more than that of control. They concluded that cellular uptake of cholesterol pullulan was enhanced by introducing cationic groups and simultaneously the quantum dot's better than the conventional cationic liposomes and these nanoparticles could be a fluorescent probe for medical imaging [47].

\subsection{Plasma expander}

Pullulan was also explored as a potential blood-plasma substitute like that of dextrans. Polymers which are highly water soluble in nature can be used as plasma expanders and pullulan is water soluble polymer. It has been reported that pullulan to be used as plasma expander with molecular weight of about $60 \mathrm{kDa}$ [16]. They observed that pullulan having high molecular weight increased the venous pressure whereas low molecular weight pullulans were rapidly excluded from the organism leaving the stage of secondary hemorrhagic shock. Thus, pullulan to be used as plasma expander, should have an effective therapeutic range of molecular weight. Shingel and his co-worker developed an anionically modified pullulan via gamma irradiation which was used as a base for blood plasma substitute [48].

\subsection{Molecular chaperons}

Moleculaes having the chaperon like activity are able to catch and release proteins. Molecular chaperons bind to denatured proteins in order to prevent irreversible aggregation. Then chaperon molecules release the proteins. Water soluble polymers such as polyethylene oxide (PEO) have been tried to increase the recovery yield of parent protein during refolding [49]. These polymers prevent the aggregation of proteins by blocking their hydrophobic surface. Nomura et al developed hydrophobized pullulan nanogels having the properties of molecular chaperons [50]. They reported the release of complexed proteins from the nanogels in their refolded forms in the presence of cyclodextrins. They concluded that these amphiphilic nanogels trap the denatured proteins and cyclodextrin acts as an effector molecule to control the binding ability of chaperon molecule to proteins.

\subsection{Hydrophobized pullulan conjugates for drug delivery: A recent development}

Pullulan hydrogels as drug delivery systems in the form of microgels and nanogels have been studied. Slow release of drug into the plasma helps in attaining the therapeutic benefits [51]. Gupta and his co-worker prepared hydrogel nanoparticles of cross-linked pullulans with glutaraldehyde in order to develop a DNA carrier system, improving the gene loading efficacy, controlled release 
properties, biocompatibility and enhanced stability. Also, hydrophobized pullulanbased nanogels interact with molecular assemblies such as liposomes and oilwater emulsion. As a result, hydrophobised pullulan conjugates were used for targeting of drugs viz., metronidazole, nicotinic acid, sulfathilzole, mitoxantrone and epirubicin [52].

Most of the cited paper in the field of hydrophobized pullulan reports the self assembly of cholesterol-bearing pullulan as stable hydrogel nanoparticles in which pullulan is non-covalently bind by associating cholesteryl moieties is shown in fig. 4.
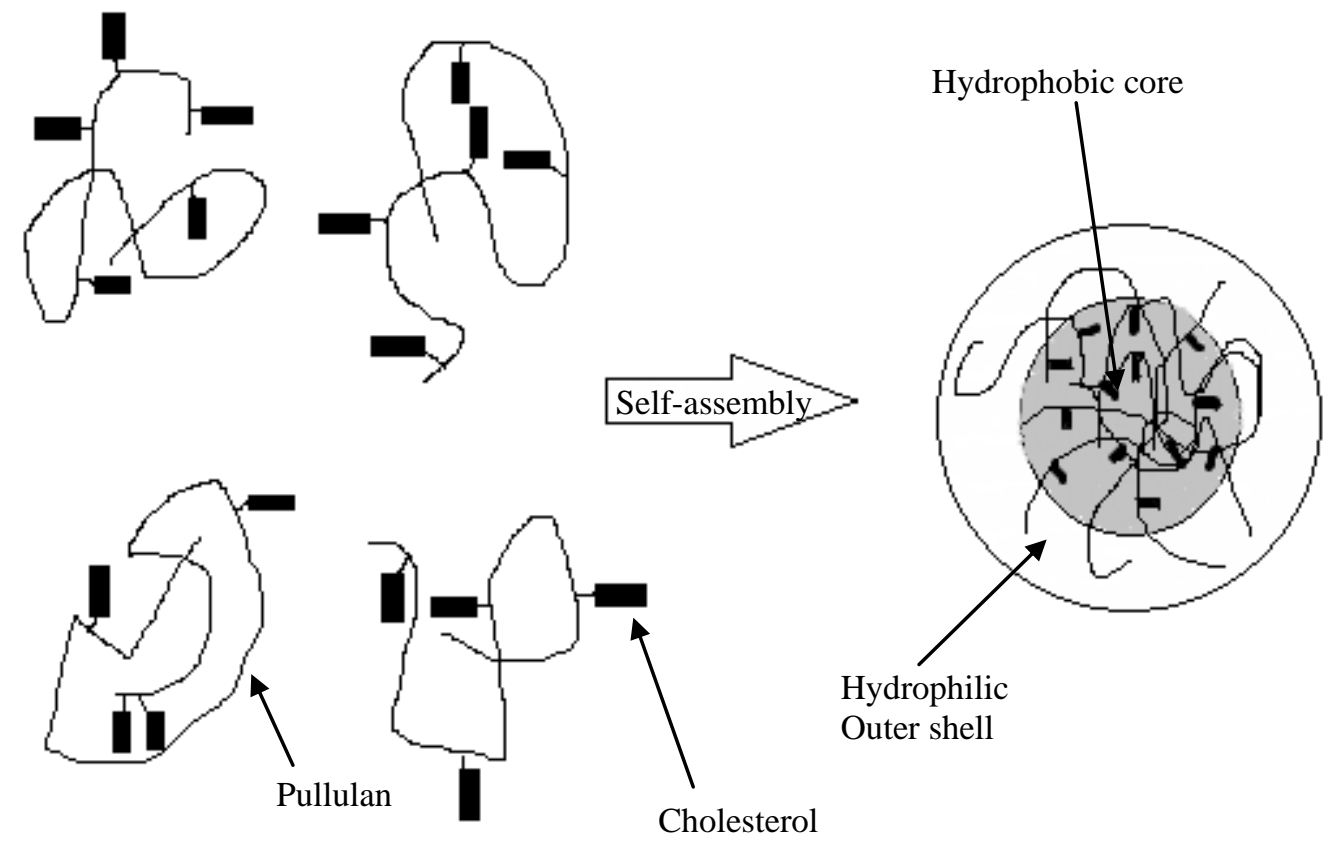

Fig. 4: Formation of cholesterol-pullulan conjugate-based nanoparticles by self aggregation in aqueous solution

\section{Recent Advances with Pullulan}

Recent advances done in pullulan are described in table 2. 
Table 2: Recent advances of Pullulan:

\begin{tabular}{|c|c|c|}
\hline Recent research & Advantages of pullulan & References \\
\hline $\begin{array}{l}\text { Fast disintegrating tablet } \\
\text { using pullulan as diluent }\end{array}$ & $\begin{array}{l}\text { Tablet hardess was found to } \\
\text { increase without increasing the } \\
\text { disintegrating time with high } \\
\text { concentration of pullulan. }\end{array}$ & {$[53]$} \\
\hline $\begin{array}{c}\text { Pullulan /Silver } \\
\text { Nanoparticles composite } \\
\text { nanospheres using electrospray } \\
\text { techniques for antibacterial } \\
\text { application. }\end{array}$ & $\begin{array}{l}\text { Controlled spherical structure by } \\
\text { controlling the concentration of } \\
\text { pullulan, enhanced antibacterial } \\
\text { activity }\end{array}$ & {$[54]$} \\
\hline $\begin{array}{l}\text { Self assembled nanogels of } \\
\text { hydrophobized pullulan }\end{array}$ & $\begin{array}{l}\text { Size stability, micelles showed } \\
\text { long term colloidal stability with } \\
\text { nearly negative neutral charge }\end{array}$ & {$[55]$} \\
\hline $\begin{array}{c}\text { Pullulan acetate coated } \\
\text { magnetic nanoparticles for } \\
\text { hyperthermia }\end{array}$ & $\begin{array}{l}\text { Nanoparticles have high magnetite } \\
\text { content, good biocompatibility, good } \\
\text { heating property in magnetic field, } \\
\text { and have evident cellular uptake by } \\
\text { tumor cells. }\end{array}$ & [56] \\
\hline $\begin{array}{l}\text { Rapid dissolving films of } \\
\text { cetirizine hydrochloride using } \\
\text { pullulan as a film forming agent }\end{array}$ & $\begin{array}{l}\text { Pullulan acted as rapid film } \\
\text { forming agent. }\end{array}$ & [57] \\
\hline
\end{tabular}

\section{Conclusion}

Pullulan has gained a lot of attention in the past few decades due to its unique properties. Pullulan is an edible and bio-polysaccharide with numerous applications in the field of food and pharmaceutical industries. The unique property of pullulan is due to its glycosidic linkage. Pullulan is synthesized by fermentation of coconut by-products, beet molasses, agro-industrial waste. Pullulan can be easily derivatized by means of chemical reaction. Pullulan has important application in the field of biomedical and pharmaceutical field viz., tissue engineering \& grafting. Pullulan has been used for liver and tumour target delivery of drug. Pullulan has the application in the field of targeting of drug to liver and cancer cells. Pullulan has occupied a niche area in food and pharmaceutical field.

\section{References}

[1] Chee K., Determination of polymer - polymer miscibility by viscometry, European Polymer Journal, 26, 1990; 423-426. 
[2] Sun Z., Wang W., Feng Z., Criterion of polymer - polymer miscibility determined, European Polymer Journal, 51, 1992; 1259.

[3] Leathers T. D., Pullulan, In: Steinbuchel A., Rhee S. K., Editors polysaccharides and polyamides in the food industry; Properties, Production and Patents, Vol. 1, Polysaccharides, Chapter 11, Wiley - VCH: Weinheim, $387-421$.

[4] Bishwambhar M., Suneetha, V., Ramalingam C., An overview of characterization and optimization of pullulan producing microorganism, South Asian journal of Experimental Biology, 1, 2011; 147-151.

[5] Li H., Chi Z., Wang X., Duna X., Ma L., Gao L., Purification and characterization of extracellular amylase from the marine yeast Aureobasidium Pullulans N13d and its raw potato starch digestion, enzyme and microbial technology, 40, 2007; 1006.

[6] Duan X., Chi Z., Wang L., Wang X., Influence of different sugars on pullulan production and activities of $\alpha$-Pyrophorylase and Glucosyltransferase involved in pullulan synthesis in Aureobasidium Pullulans Y68, Carbohydrate polymers, 73, 2008; 587.

[7] Zheng W., Campbell B. S., McDougall B. M., Seviour R., J., Effects of melanin on the accumulation of exopolysaccharides by Aureobasidium Pullulans grown on nitrate, Bioresource Technology, 99, 2008; 7480.

[8] Bender H., Lechmann J., Wallenfells K., Pullulan, ein extracellular glucans von Pullularia pullulans, Biochemica Biophysica Acta, 36, 1959; 309-316.

[9] Suneetha V., Sindhuja K. V., Sanjeev K., Screening, characterization and optimization of pullulan producing microorganisms from plant leaves in chitoor district, Asian Journal of Microbiology Biotechnology and environmental sciences, 12, 2010; 149-155.

[10] Alemzadeh L., Vossoughi M., Naimpour F., Bioploymer production and kinetics, International seminar of polymer science and technology, Shiraz, I.R. IRAN, 1994; 449-455.

[11] Wallenfels K., Bender H., Kelich G., Bechtler G., On pullulan, the glucan of the slime coat of Pullularia pullulans, Angew. Chem., 73, 1961; 245-246.

[12] Bouveng H. O., Kiessling H., Lindberg B., McKay J., Polysaccharides elaborated by Pullularia pullulans I, The neutral glucans synthesized from sucrose solution, Acta. Chem. Scand., 16, 1962; 615-622.

[13] Carolan G., Catley B. J., McDougal F. G., The location of tetrasaccharide units in pullulan, Carbohydr. Res., 114, 1983; 237-243.

[14] Rekha M. R., Sharma C. P., Blood compatibility and in-vitro transfection studies on cationically modified pullulan for liver cell targeted gene delivery, Biomaterials, 30, 2009; 6655-6664.

[15] Mishra B., Vuppu S., Rath K., The role of microbial pullulan, a biopolymer in pharmaceutical aaproaches: a review, Journal of Applied Pharmaceutical Sciences, 1(6), 2011; 45-50. 
[16] Tsijisaka Y., Mitsushashi M., Pullulan in industrial gum: Polysaccharides and their derivatives; Whistler R., BeMiller J. N., Eds., Academic: San Diego, 1993; 447-460.

[17] Fujii N., Shinohara S., Polysaccharides produced by Aureobasidium pullulans, FERM - P4257 II, Toxicity test and anti-tumour effect, Kenkyu Hokoku - Miyazaki Daigaku Nogakubu, 33, 1986; 243-248.

[18] Kimoto T., Shibuya T., Shiobara S., Safety studies of a novel starch, pullulan: Chronic toxicity in rats and bacterial mutagenecity, Food Chem. Toxicol, 35, 1997; 323-329.

[19] 19) Shingle K. I., Current knowledge on biosynthesis, biological activity and chemical modification of the exopolysaccharides, pullulan, Carbohydr. Res. 339, 2004; 447-460.

[20] Youssef F., Biliaderis C. G., Roukas T., Enhancement of pullulan production by Aureobaisdium pullulans in batch culture using olive oil and sucrose as carbon source, Appl. Biochem. Biotechnol., 74, 1998; 13-30.

[21] Thirumavalavan K., Manikkadan T. R., Dhanasekar R., Pullulan production from coconut by-products by Aureobasidium pullulans, African journal of biotechnology, 8(2), 2009; 254-258.

[22] Goksungur Y., Ucan A., Guvenc U, Production of pullulan from beet molasses and synthetic medium by A. pullans, Turk J. Biol., 28, 2004; 23-30.

[23] Israilides C. J., Smith A., Bambalov G., Production of pullulan from agroindustrial wastes, Proceedings of the sixth European Congress on Biotechnology 2, Frienz, Italy, 1993; 362.

[24] Shin Y. C., Kim Y. H., Lee H. S., Cho S. J., Byum S. M., Production of exopolysaccharide pullulan from inulin by a mixed culture of Aureobasidium pullulans and Kluyveromyces fragilis, Biotechnology and Bioengineering, 33, 1989; 129-133.

[25] Israilides C. J., Smith A., Harthill J. E., Barnett C., Bambalov G., Scanlov B., Pullulan content of the ethanol precipitate from fermented agro-industrial wastes, Applied Microbiology and Biotechnology, 49, 1998; 613-617.

[26] Israillides C. J., Scanlon B., Smith A., Jumel K., Harding S. E., Characterization of pullulans produced from agro-industrial wastes, Carbohydrate polymers, 25, 1994b; 203-309.

[27] Saha B. C., Bothast R. J., Starch conversion by amylases from Aureobasidium pullulans, Journal of Industrial microbiology, 12, 1993; 413416.

[28] Israilides C. J., Vlyssides A. G., Mouraferi V. N., Karvouni G., Olive oil waste water treatment with the use of an electrolysis system, Bioresource Technology, 61, 1977; 163-170.

[29] Shabtai Y., Mukmenev J., Enhanced production of pigment-free pullulan by a morphogenetically arrested Aureobasidium pullulans (ATCC 42033) in a two stage fermentation with shift from soyabean oil to sucrose, Applied Microbiology and Biotechnology, 43, 1995; 595-603. 
[30] Roukas T., Biliaderis C., Evaluation of carbo pod as a substrate for pullulan production by Aureobasidium pullulans, Applied Biochemistry and Biotechnology, 55, 1995; 27-44.

[31] Taguchi R., Sakano Y., Kikuchi Y., Sakuma M., Kobayashi T., Synthesis of pullulan by acetone-dried cells and cell-free enzymes from Pullularia pullulans and the precipitation of lipid intermediates, Agricultural and biological chemistry, 37(7), 1972; 1635-1641.

[32] Bataille I., Meddahi-Pelle A., Visage C. L., Letourneur D., Chaubet F., Pullulan for biomedical use, chapter 4, 145-182.

[33] Souguir Z., Roudesli S., Picton L., Cerf D. L., About-Jaudet E., European Polymer Journal, 43, 12, 2007; 4940.

[34] Henni-Silhadi W., Deyme M., Hoyos M. R., Cerf D. L., Picton L., Rosilio V., Colloid and polymer Science, 286, 11, 2008; 1299.

[35] Bataille I., Huguet J., Muller G., Mocanu G., Caprov A., International Journal of Biological of Macromolecules, 20, 3, 1997; 179.

[36] Legros M., Dulong V., Picton L., Cerf D. L., Polymer Journal, 40, 12, 2008; 1132.

[37] Mahner C., Lechner M. D., Nordmeier E., Carbohydrate Research, 331, 2, $2001 ; 203$.

[38] Alban S., Schauerte A., Franz G., Carbohydrate Polymers, 47, 3, 2002; 267.

[39] Na K., Lee D. H., Hwang D. J., Park H. S., Lee K. H., Bae Y. H., pHsensitivity and $\mathrm{pH}$ - dependent structural change in polymeric nanoparticles of poly (vinyl sulfadimethoxine)-deoxycholicacidconjugate, European Polymer Journal, 42, 2006; 2581-2588.

[40] Gao J., Yu J., Wang W., Chang L., Tian R., Graft copolymerization of starch - An initiated by potassium permanganate, Journal of Applied Polymer Science, 68, 1999; 1965-1972.

[41] Kin E. J., Cho S. H., Yuk S. H., Polymeric microspheres composed of $\mathrm{pH} /$ temperature - sensitive polymer complex, Biomaterials, 22, 2001; 24952499.

[42] Kurkuri M. D., Aminabhavi T. M., Poly(vinyl alcohol) and poly(acrylic acid) sequential interpenetrating network $\mathrm{pH}$ - sensitive microspheres for the delivery of diclofenac sodium to the intestine, Journal of Controlled Release, 96, 2004; 9-20.

[43] Gheorghe F., Marieta C., Paolo A., Preparation and characterization of pHand temperature-sensitive pullulan microspheres for controlled release of drugs, Biomaterials, 29, 2008; 2767-2775.

[44] Xi K., Tabata Y., Uno K., Yoshimoto M., Kishida T., Sokawa Y., Ikada Y., Liver targeting of interferon through pullulan conjugation, Pharmaceutical Research, 13, 1996; 1846-1850.

[45] Scomparin A., Salmosa S., Bersani S., Satchi-Fainaro R., Caliceti P., Novel folated and non-folated pullulan bioconjugates for anticancer drug delivery, European Journal of Pharmaceutical Sciences, 42, 2011; 547-558. 
[46] Hosseinkhani H., Aoyama T., Ogawa O., Tabata Y., Liver targeting of plasmid DNA by pullulan conjugation based on metal coordination, Journal of Controlled release, 83, 2002; 287-302.

[47] Hasegawa et al, Macromol. Biosci., 5, 2005; 710-716.

[48] Shingel K. I., Petrov P. T., Colloid Polym. Sci. 280, 2002; 176-182.

[49] Cleland J. L., Hedgepeth C., Wang D. I. C., Polyethylene glycol enhanced refolding of bovine carbonic anhydrase B., J. Biol. Chem., 267, 1992; 1332713334.

[50] Nomura Y., Ikeda M., Nozomi M., Yamaguchi N., Aoyama Y., Akiyoshi K., Protein refolding assisted by self-assembled nanogels as novel artificial molecular chaperone, FEBS Letters, 553, 3, 2003; 271-276.

[51] Wooram P., Kyoung S. K., Byoung-chan B., Young-Heui K., Kun N., Cancer cell specific targeting of nanogels from acetylated hyaluronic acid with low molecular weight, European Journal of Pharmaceutical Sciences, 40, 2010; 367-375.

[52] Gupta M., Gupta A. K., Hydrogel pullulan nanoparticles encapsulating pBUDLacZ plasmid as an efficient gene delivery carrier, Journal of controlled release, 99, 2004; 157-166.

[53] Patel D., Chauhan M., Patel R., Patel J., Optimization of fast disintegration tablets using pullulan as diluent by central composite experimental design, 2012; DOI: 10.4103/0975-7406.94150.

[54] Islam Md. S., Islam Md. A., Sarker M., Karim Md. M., Masum S., Yeum J. H., Fabrication of Pullulan/Silver nanoparticle composite nanospheres using electrospray technique for antibacterial applications, International Journal of Basic \& Applied Sciences, 11(1), 2011; 59-69.

[55] Ferreira S. A., Coutinho P. J. G., Gama F. M., Synthesis and characterization of self-assembled nanogels made of pullulan, Materials, 4, 2011; 601-620.

[56] Gao F., Cai Y., Zhou J., Xie X., Ouyang W., Zhang Y., Wang X., Zhang X., Wang X., Zhao L., Tang J., Pullulan acetate coated magnetite nanoparticles for hypothermia: Preparation, Characterization and In -Vitro Experiments, Nano. Res., 3, 2010; 23-31.

[57] Mishra R., Amin A., Formulation and characterization of rapidly dissolving films of cetrizine hydrochloride using Pullulan as film forming agent, Indian journal of pharmaceutical education and research, 45(1), 2011; 71-77. 